\title{
Influencer Marketing and Traditional Marketing in China: \\ How Does Influencer Marketing in the Leisure Food Industry Affect Purchase Intention
}

\author{
Xiaoyu $\mathrm{Guo}^{1, *}$, Weiyue $\mathrm{Li}^{2}$, Hongrui $\mathrm{Hu}^{3}$, Lisi He${ }^{4}$, Shengjie $\mathrm{Li}^{5}$ \\ ${ }^{1}$ Forsyth country day school, Lewisville, NC 27023, United States \\ ${ }^{2}$ London College of Fashion, University of the Arts London, London, W1G 0BJ, UK \\ ${ }^{3}$ Shrewsbury School, Severn hill, Shrewsbury Shropshire, SY3 8SG UK \\ ${ }^{4}$ GuangDong country garden school, Guang Dong, 528300, China \\ ${ }^{5}$ Wuhan Britain-China School, wuhan, 430010, China \\ *Corresponding author email: carolguo@fcds.org
}

\begin{abstract}
In the past few years, due to the popularization of intelligent technology and the impact of fragmented media on information dissemination, emerging influencer marketing has gradually replaced the traditional marketing model and occupied a dominant position in the market. The aim of this study is to what extent influencer marketing has affected consumers' purchase intentions, with the main focus on the leisure food industry. This study discusses the factors that influence consumer decision making in terms of interactivity, celebrity expertise and cross-platform cooperation. We conducted a questionnaire survey among 100 participants and analyzed the effects of influencer marketing on their decision making of leisure food, with the comparison of traditional marketing. Finally, implications for research and future practices are also discussed.
\end{abstract}

Keywords: Influencer marketing, leisure food, China, purchase intention, interactivity, celebrity worship, cross-channel cooperation

\section{INTRODUCTION}

Nowadays, the prevalence of social media dramatically affects the way people receive information on a daily basis. Approximately three billion people worldwide now use social media monthly, 90 percent of whom access their chosen platforms on mobile devices[1-2]. With appearance of different social media platforms, social influencers and celebrities also form grandly. By sharing a variety of content and opinions, influencers form their own fan group which becomes a strong marketing pool. Indeed, Chinese Internet celebrities' economy is expected to be worth RMB 58 billion in 2016 (US\$ 8.76 billion), more than China's cinema box office in 2015[3]. Today, nearly $75 \%$ of marketers are using influencers to spread word of mouth (WOM) about their products and brands on social media. Influencer marketing is often considered critical to strengthening online brand engagement[4].
Besides, influencer marketing is one of the important components of the leisure food industry in China. In detail, the number of Chinese food e-commerce retail users reached 161 million, and in the first half of 2021, the number of Chinese food e-commerce users reached 277 million, with a year-on-year growth of $29.4 \%$ [5] Indeed, the potential market for the local leisure industry in China is huge. Therefore, it is important to explore different influencer advertising strategies that affect consumers' decisions and purchase intention. The contribution of this paper is to explore the relationship between influencer marketing and the purchase intention of consumers in the Chinese leisure food industry.

The format of the this paper structured as follows. First of all, we provide a literature review on the transformation of traditional marketing to influencer marketing in China's leisure food industry. Next, we provide a survey to state the three beneficial aspects of influencer marketing in the China leisure food industry. 
Third, we discuss the benefits of influencer marketing in three different aspects: the interaction between influencer and consumer, celebrity worship, and cross-channel cooperation. At the last, we illustrate the future prospect of influencer advertising in the China leisure food market.

\section{LITERATURE REVIEW}

Leading enterprises of social network media have successively launched influencer e-commerce platforms, gradually forming a complete industrial chain ecology. Several theories about the benefits of influencer marketing over traditional marketing have been proposed. Scholars defined social media influencer marketing as a viral marketing approach that an online personality shapes consumers' attitudes through tweets, posts, blogs, or any other formats of communication on social media[6]. Indeed, there are three key benefits of influencer marketing, these are interaction between influencer and consumer, celebrity worship, and crosschannel cooperation[7].

First, live-streaming influencers and vlogging influencers, because of their online activism, and 'lively' interactions with their followers, become an increasingly important marketing tool for companies to reach the greater internet user masses[8]. Social media influencers share their lives, tastes, and hobbies on different online platforms. They interact with a large portion of the user to shape and spread their trends. Compared with traditional marketing, influencer marketing urges consumers to engage with the advertisement.

Second, celebrity worship has been explored in prior research. Indeed, there is a positive interaction between celebrity worship and purchase intention. By interacting with celebrities through social media, the consumer can satisfy their inner emotional needs, such as emotional resonance, belonging, and establish long-term mutually beneficial relationships. Individuals having a parasocial association with celebrity are more persuasive and it is similar to that of trusting a true friend's advice[9].

Third, cross-channel promotions include marketing, organic promotions, and advertisement on multiple channels. Put your products on YouTube, Instagram, Facebook, and Pinterest to build a comprehensive outlook for your items. Also using this cross-channel promotion method might help you attract interested shoppers to this platform leading to higher scales[10]. Indeed, cross-channel provides a consistent, integrated experience for the consumer and maximum exposure of the product. The proportion of consumers actively sharing/forwarding product-related information or participating in/forming related communities within three months before and after purchase is as high as $77 \%[11]$. In the traditional marketing model, only brands decide what and how they want to disseminate their advertisement. Cross-channel marketing can satisfy consumers' intrinsic motivation through cross-platform cooperation, and encourage consumers to actively communicate and promote the brand.

\section{METHODOLOGY}

\subsection{Sampling data collection}

The research is carried out by administering an online questionnaire. During the one-week survey, we published 100 questionnaires about the behavior habits of food consumers on the Internet. We invited 50 males and 50 females of different ages online as our consumer sample and received 100 valid answers. The survey questions include the collection of basic consumer information, consumer attitudes towards traditional markets and web celebrity marketing, and the three main aspects of our research, interaction between influencer and consumer, celebrity worship and cross-platform collaboration. The details of the scales are given in Table 1 .

Table 1. consumer buying habits survey in China leisure food market

\begin{tabular}{|c|c|c|}
\hline Construct & Frequency & Percentage \\
\hline \multicolumn{3}{|l|}{ Gender } \\
\hline Female & 50 & 50.0 \\
\hline Male & 50 & 50.0 \\
\hline Total & 100 & 100.0 \\
\hline \multicolumn{3}{|l|}{ Age (in years) } \\
\hline Under 18 & 26 & 26.0 \\
\hline 18 to 35 & 38 & 38.0 \\
\hline 36 and above & 36 & 36.0 \\
\hline
\end{tabular}




\begin{tabular}{|c|c|c|}
\hline Total & 100 & 100.0 \\
\hline \multicolumn{3}{|c|}{$\begin{array}{l}\text { Are you attracted to traditional marketing or influencer marketing while you are making the } \\
\text { purchase decision? }\end{array}$} \\
\hline Traditional marketing & 36 & 36.0 \\
\hline Influencer marketing & 64 & 64.0 \\
\hline Total & 100 & 100.0 \\
\hline \multicolumn{3}{|c|}{ Would you buy the food when you are watching the eating live-stream? } \\
\hline Yes & 54 & 54.0 \\
\hline No & 46 & 46.0 \\
\hline Total & 100 & 100.0 \\
\hline \multicolumn{3}{|c|}{ Would you buy food recommended by an influencer because you like or trust him/her? } \\
\hline Yes & 59 & 59.0 \\
\hline No & 41 & 41.0 \\
\hline Total & 100 & 100.0 \\
\hline \multicolumn{3}{|c|}{$\begin{array}{l}\text { Is it the food endorsed by idols that appeals to you more or recommended by food } \\
\text { professionals? }\end{array}$} \\
\hline Idols & 19 & 19.0 \\
\hline Food professional & 81 & 81.0 \\
\hline Total & 100 & 100.0 \\
\hline \multicolumn{3}{|c|}{ Do you open links from other apps and jump to other platforms? } \\
\hline Yes & 57 & 57.0 \\
\hline No & 43 & 43.0 \\
\hline Total & 100 & 100.0 \\
\hline
\end{tabular}

\subsection{Data analysis and result}

As shown in Table 1, the transformation from traditional marketing to influencer marketing is remarkable. Due to the rise of social media, KOL (key Opinion Leader, similar to influencer) from different platforms plays an essential factor in consumer decisions. In the survey, people are more likely to watch KOL instead of watching television and advertising panels. People are more willing to listen to influencer's opinions while making the purchase decision. According to the distribution of age, the preference of influencer marketing is mainly young people. Specifically, consumers believe the eating live stream (aka Mukbang) positively affects their purchase intention of food. Also, consumers' trustiness towards influencers and celebrities makes them more willing to buy the food that influencers and celebrities recommend, and people state a professional from the food industry also makes them more likely to purchase the food. Furthermore, discounts from the different platforms stimulate the willingness to buy.

\section{DISCUSSION}

\subsection{Interactivity}

Parasocial interactions and parasocial relationships with social media influencers should be especially prominent and meaningful, compared with those with celebrities who appear only in traditional media[12-14]. Instead of using traditional advertising to deliver the information in a single pass, the interaction between influencer and consumer forms a tight relationship, which makes the consumer more willing to take a part in 
purchase intention. In China, after the appearance of live broadcasts in 2017, many people sell leisure food on live streaming, such as the mukbang on Bilibili. Mukbang is an "eating life" that originated in South Korea. After becoming popular in South Korea, many influencers in China also broadcast the live show on Bilibili and other live broadcasts. When a blogger started Mukbang, consumers who had previously clicked on the Mukbang hashtag received a notification about streaming. In the process of watching the live broadcast, by combining bodies' actions (eating performance), speech, and written texts under their videos, the Mukbang show created an inter-communicating internet community[15]. Indeed, the platform live broadcast makes the interaction between influencer and consumer more convenient. Using Hashtags can directly obtain brand account clicks, participation, and potential users. Replying to the comments under the brand account on time can also increase the customer's favourability and enhance interaction with the customer[16]. Therefore, interactivity can deliver information more comprehensively which stimulates the potential consumer.

In addition, striving for emotional contagion with consumers generates a close relation between influencer and consumer. In detail, when we are around other people, especially crowds, the limbic system releases neurochemicals that connect us at an emotional level. The capacity for empathy and non-verbal communication is called limbic resonance aka "emotional contagion"[17]. Indeed, fostering a personal connection with consumers brings a huge asset to the influencer and brand. For instance, Ziqi Li, a Chinese influencer in the leisure goods industry, showing the leisure food production process in a vlog pattern. The organized and relaxed vlog style attracts a lot of people, especially the group around twenty-six to thirty-four who have a lot of pressure at work[18]. By building personal connections with consumers, people are more willing to find out about the product. Ziqi Li's leisure goods store makes 160 million profit every year[18]. Moreover, Ziqi Li jointly named Forbidden City and launched the chili sauce on Chinese national day, which sold sixty thousand chili sauces every month in 2020[18]. Indeed, the collaboration promotes contemporary Chinese Patriotism, which builds the emotional contagion with the consumer. Therefore, using emotional contagion to interact with consumers positively promotes the purchase intention.

\subsection{Celebrity Worship}

Celebrity worshipers are the people who exhibit an extremely profound adoration and devotion for a celebrity[19]. It is a form of parasocial interplay in which a person becomes preoccupied with one or more celebrities[20]. Compared with traditional marketing, the interaction of influencer marketing makes celebrity worship more reliant. In this study, we observed similar brand styles and celebrity images (e.g., attractiveness, credibility and expertise) increase consumers' willingness to buy.

One of the factors that establish the celebrity image is the attractiveness of celebrities. Attractiveness also entails concepts such as intellectual skills, personality properties, way of living, athletic performances and skills of endorsers[21]. For instance, Junkai Wang, a Chinese artist who debuted as a child star, has become the spokesperson for the Chinese milk tea brand Xiangpiaopiao. Indeed, the young and fashionable image of Junkai Wang matches with Xiangpiaopiao's transformation to the young consumer market. According to a statistics report, Junkai Wang's endorsement of milk tea has been viewed more than one billion times on social media platform Weibo[22]. The brand through holding the spokesperson meeting, providing a series of activities such as buying milk tea, obtaining peripheral products, winning the meeting tickets, supporting the idol, attracting Wang Junkai's huge fan base, bringing a great improvement to the popularity and reputation of Xiangpiaopiao. At the same time, the positive corporate image of Xiangpiaopiao also makes Junkai Wang's business value icing on the cake, reaching a win-win situation. Therefore, brand marketing not only enhances the popularity through celebrity endorsement, but also establishes a positive connection between the product and the celebrity value, and ultimately influences and induces the consumer's purchase decision.

In addition, other factors in image building are the celebrity's credibility and expertise, which often supplement each other. Credibility is "the extent to which the recipient sees the source as having relevant knowledge, skills, or experience and trusts the source to give unbiased, objective information"[23]. If a celebrity is more expert and experienced in the endorsed field, he/she will easily gain trust, positive recognition[24]. For example, Mr. Chua Lam, a well-known food critic, has been writing about food for nearly 40 years. The dim sum dishes he developed have become popular across the country, opening 16 restaurants in two years and becoming popular with the public. Through numerous media, KOL promoted "the product of Chua Lam" on various social platforms, which became popular all over the country. Thus, the source or celebrity that is a specialist has been found to be more persuasive [25] and generates more purchase intentions[26].

\subsection{Cross-channel Cooperation}

Thanks to technology development, online purchasing apps have flourished in China. To promote sales, cross channel cooperation such as link sharing and page skipping develop, provide convenience for 
customers, and therefore generate profits. Nowadays in China, there are a variety of apps for online purchasing such as Taobao, pdd and Meituan, resulting in competition. Under the circumstances, apps deliberately develop and improve cross-channel cooperation.

Compared to traditional advertisements, influencers advertising is always available and can target customers more precisely. In order to reach more potential customers, influencers now use more social media to attract traffic. Influencers have their followers that are specifically in one area while they introduce the products within that area. Therefore, almost all followers are potential customers, so the influencer can bring more new customers.

In addition, influencers who introduce products to their fans will put a link at the bottom of their video or live streams therefore consumers purchase while they are convinced by the influencer. The vlog on popular platforms attracts more potential customers to view the product and increases the fame of the brand. Meanwhile, the link itself makes the process of purchasing as well enormously convenient, consumers only have to click and pay, and almost all of them arrive within 2 days[27]. Such practice largely improves the efficiency of converting potential customers to direct purchases.

Moreover, online shops enhance customer loyalty by encouraging consumers to provide vivid, positive comments. People can get 5-10-yuan coupons or cash in return for the positive comment. Then, such coupons can be used to offset part of the future purchase. Furthermore, for all smartphones now, apps switch pages between each other that promote and create an amenity for consumers. As a result, sales have once again increased, and more customers are attracted.

As a consequence, and contribution of all these positive factors, the mature online purchasing ecosystem in China now has increased the rate of increase of total net sales by at least $10 \%$ for the last 3 years[28]. In Taobao, the biggest online shopping platform in China, during the year 2019's 'double11' (11th of November) activity, the total sale reached 20billion yuan (around 3.1 billion US dollars), while the number of people watching live promotion event increased over $130 \%$ compared to the year before and developed around 10 live streams that made over 100million yuan (around 15.5 million US dollars)[29]. Another great example is WeChat, which is one of the most popular apps in China, covering areas of social media, mobile payment, and ports to other online purchasing apps. Since WeChat is a social media, people send messages to each other including links that direct people to other apps and then to purchase. These useful features enable people to chat with friends and purchase at the same time and therefore generate sales. In addition to being the biggest social media app in China, WeChat is also the second biggest online payment method in China, containing around $40 \%$ market share throughout
2019[30]. Due to the market share of WeChat Pay and the ports in WeChat connect to other apps, consumers are allured to purchase or even install the app and become long-term customers.

\section{CONCLUSION AND FUTURE PROSPECT}

In this paper, we ask the question of the benefit of influencer marketing over traditional marketing in the Chinese leisure food industry. According to China CMG, we review the benefits of influencer marketing in three aspects: interaction between influencer and consumer, celebrity worship, and cross-channel cooperation (Lin, 2021) [7]. In detail, we talk about specific examples in the Chinese leisure food industry, and we also use a survey to confirm our point of view. To conclude, this report result can be used for leisure good company, especially for the business manager. The key lesson to take away from this report is that interaction between influencer and consumer, celebrity worship, and crosschannel cooperation have a positive relationship with consumer purchase in the leisure food industry.

Additionally, with the rise of Virtual Reality and 5G, the virtual influencer is improving day by day. Specifically, the virtual influencer can fit the specific needs of brands and companies. The new and original technology can attract young people, which increases the interactivity of influencers and consumers, also using the perfect fit of brand images and cross-channel cooperation strategy, the virtual influencer has better potential in order to attract purchase intention. In summary, the current influencer marketing in the Chinese leisure food industry is growing steadily, and we are curious to see how this influencer marketing report can help the future business market.

\section{REFERENCES}

[1]Chahal, M. (2016, January 8). "Four Trends That Will Shape Media in 2016." Retrieved March 9, 2018, from the Marketing Week website: https:// www.marketingweek.com/2016/01/08/four-trendsthat-will-shape- media-in-2016/

[2]Kemp, S. (2018, January 30). "Digital in 2018: World's Internet Users Pass the 4 Billion Mark." Retrieved from the We Are Social website: https:// wearesocial.com/blog/2018/01/global-digitalreport-2018

[3]China Daily. (2017). China's internet celebrity economy is bigger than cinema. Retrieved July 1, 2017, from http:/www.china daily.com.cn/china/201609/17/content_26812402.htm.

[4]Newberry, Christina (2018), "The Complete Guide to 
Influencer Mar- keting," (accessed February 28, 2019), https://blog.hootsuite.com/ influencermarketing/.

[5]Mingyue Liu "Food e-commerce market research 2021 food e-commerce market situation and food ecommerce industry development report"06.25.2021, available at https://m.chinairn.com/hyzx/20210625/114533105. shtml

[6]Ferguson, R. (2008). Word of mouth and viral marketing: Taking the temperature of the hottest trends in marketing. Journal of Consumer Marketing, 25(3)

[7]Lin, Yan. "Challenge and Enlightenment of Internet red marketing to traditional media advertising management" July 7th, 2021, journal of China $C M G, \quad$ retrieved from https://mp.weixin.qq.com/s/GVa6oo1UHA6e4tnsH ykLmA

[8]Babenskaite G. (2019) Mukbang Influencers: Online eating becomes a new marketing strategy. http://www.diva-

portal.org/smash/get/diva2:1332196/FULLTEXT0 1.pdf

[9]Forrester. (2012). North American Technographics Online Benchmark survey. https://www.forrester.com

[10]Wilson. (n.d.). Mastering Etsy - The Entrepreneurs Guide To Creating A Thriving Etsy Business Online by Adidas Wilson. Scribd. https://www.scribd.com/book/375712765/Masterin g-Etsy-The-Entrepreneurs-Guide-To-Creating-AThriving-Etsy-Business.

[11]Wu, W., \&amp; Langer, D. (2020, February 4). Key Takeaways from BCG x Tencent 2020 China Social Retail Playbook. Jing Daily. https://jingdaily.com/key-takeaways-from-bcg-xtencent-2020-china-social-retail-playbook/.

[12]Chung, S., and H. Cho. "Fostering Parasocial Relationships with Celebrities on Social Media: Implications for Celebrity Endorsement." Psychology \& Marketing 34, 4 (2017): 481-495.

[13]Djafarova, E., and C. Rushworth. "Exploring the Credibility of Online Celebrities' Instagram Profiles in Influencing the Purchase Decisions of Young Female Users." Computers in Human Behavior 68 (2017): 1-7.

[14]Yuksel, M., and L. I. Labrecque. “'Digital Buddies': Parasocial Interactions in Social Media." Journal of Research in Interactive Marketing 10, 4 (2016): 305-320.
[15]Choe, H. (2019) 'Eating together multimodally: Collaborative eating in mukbang, a Korean live stream of eating'. Language in Society, Vol. 48 (2): $171-$

172.https://www.emarketer.com/content/influencer -marketing-in-china [Accessed 19/04/2019]

[16]Ki, C., \& Kim, Y. (2019). The mechanism by which social media influencers persuade consumers: The role of consumers' desire to mimic. Psychology \& Marketing, 36(10), 905-92

[17]Richard Medic(2021). "Limbic Resonance - the Science behind the Success of Youtubers." Brendan Gahan, 18 June 2021, brendangahan.com/limbicresonance-science-behind-successyoutubers/\#: :text=The $\% 20$ capacity $\% 20$ for $\% 20 \mathrm{e}$ mpathy\%20and,That's\%20limbic\%20resonance.

[18]Nanyang Baihe technology(2020) 'Ziqi Li’s gold absorbing ability is impressive: the estimated annual income is 168 million yuan".https://m.sohu.com/a/401242208_10000911 1

[19]Raviv, A., Bar-Tal, D., Raviv, A., \& Ben-Horin, A. (1996). Adolescent idolization of pop singers: Causes, expressions, and reliance. Journal of Youth and Adolescence, 25(5), 631-650. doi:10.1007/BF01537358

[20]McCutcheon, L. E., Ashe, D. D., Houran, J., \& Maltby, J. (2003). A Cognitive profile of individuals who tend to worship celebrities. The Journal of Psychology, 137, 309-322. doi:10.1080/00223980309600616

[21]Erdogan, B.Z. (1999). Celebrity endorsement: A literature review. Journal of Marketing Management, Vol. 14, 291-314

[22]Wangyi News. (2020). Wang Junkai's endorsement of the Xiang Piao topic has been read more than one billion ties. https://c.m.163.com/news/a/F3C173MH0517853O .html?spss=newsapp

[23]Belch, G., Belch, M., (1994). Introduction to advertising and promotion: An integrated marketing communications perspective, ed. 3, Irwin: Homewood, 189-192

[24]Braunsberger, K. (1996). The effects of source and product characteristics on persuasion. Arlington, TX: Doctoral dissertation, University of Texas at Arlington.

[25]Aaker, J. (1997). Dimensions of brand personality. Journal of Marketing Research, Vol. 34, No. 3, 347 356

[26]Ohanian, R. (1991). The impact of celebrity 
spokesperson's perceived image on consumers' intention to purchase. Journal of Advertising Research, Vol. 31, No. 1, 46-52

[27]HaoChen Chong "delivery enters 48 hours era: 2020 delivery industry analysis" China irn.com, 13.9.2020, available at https://www.chinairn.com/hyzx/20200913/123550 978.shtml

[28]"China leisure food industry development and future marketing: trillions of leisure food market, branding concentration on the way" 09.05.2020, chyxx.com, available

at https://www.chyxx.com/industry/202005/860578.h tml

[29]"Influencers with Matthew effect: future of influencer marketing" baijiahao.baidu.com, 15.12.2019, available https://baijiahao.baidu.com/s?id=16529447851480 $00188 \&$ wfr $=$ spider $\&$ for $=$ pc

[30]39degrees net "market proportion of Alipay and Wechat Pay" 13.7.2019, available at https://m.sohu.com/a/326620569_115473/?pvid=0 00115_3w_a 